\title{
The role of social support and emotional exhaustion in the association between work-family conflict and anxiety symptoms among female medical staff: a moderated mediation model
}

\author{
Hui Zhang ${ }^{1}$, Leiwen Tang ${ }^{1}$, ZhiHong Ye ${ }^{1 *}$, Ping Zou², Jing Shao ${ }^{1}$, Man Wu ${ }^{3}$, Qi Zhang ${ }^{1}$, Guojin Qiao ${ }^{4}$ and \\ Shaoyu $\mathrm{Mu}^{5}$
}

\begin{abstract}
Background: Limited work has been done to explain how work-family conflict is related to anxiety symptoms and the roles of emotional exhaustion and social support may play.

Methods: Based on a sample of 764 female nurses and physicians, a model was tested in which emotional exhaustion served as a mediator and social support was regarded as a moderator between work-family conflict and anxiety symptoms.

Results: This current study supported a moderated mediation model where the relationship between work-family conflict and anxiety symptoms via emotional exhaustion was weakest for female medical staff who reported high levels of social support.

Conclusions: This study contribute to providing an understanding of how and when work-family conflict affects anxiety symptoms. The results implicate a wide range of interventions aimed at promoting mental wellbeing among female medical staff for policymakers and individuals.
\end{abstract}

Keywords: Anxiety symptoms, Work-family conflict, Emotional exhaustion, Social support, Female medical staff

\section{Background}

According to the "Healthy China 2030" program, a call-toaction highlighted for 2016-2030 is the need to "reduce mental disorders, burnout, and job-related stress, enhance stress management and introduce screening programs to promote wellbeing in the workplace" http://www.nhc.gov. cn/guihuaxxs/s3586s/201610/a2325a1198694bd6ba42d6e4

7567daa8.shtml. Therefore, a comprehensive understanding

\footnotetext{
* Correspondence: 3192005@zju.edu.cn

'Zhejiang University School of Medicine Sir Run Run Shaw Hospital, Hangzhou 310016, Zhejiang, China

Full list of author information is available at the end of the article
}

and effective interventions for mental health in the workplace are needed. As there has been an increase in female participation in the labor market, the World Health Organization states that more emphasis should be placed on women's mental health concerns, such as anxiety, depression, and somatic complaints, which disproportionately affect females https://www.who.int/mental_health/prevention/genderwomen/en/. One possible explanation for this distribution of mental health concerns may be that females commonly suffer the double burden of work and family responsibilities, separation from their children, and a lack of family or co-worker support [1]. 
The medical profession can be one of the most stressful and demanding careers, which can lead to negative effects on mental health among physicians and nurses. A large and growing body of literature has shown that physicians and nurses have a higher prevalence of mental health disorders (eg., symptoms of depression, anxiety, and suicidal ideation) compared with the general population because of a heavy workload, the morbidity and mortality of patients, and challenging daily work routines [2]. Anxiety, which is one of the most common psychological disorders, can be more prominent among female medical professionals [3]. This mental health issue has a detrimental impact on professional performance and well-being, and may lead to issues with patient safety. A wide range of factors are likely to have an impact on the prevalence of mental disorders among medical professionals, including burnout, social support, and role stress [4].

Work-family conflict can be defined as, "An inter-role conflict in which the role pressures from the work domain are, to some extent, incompatible with the family domain" [5]. Work-family issues serve as a vital factor within the domain of occupational health psychology, especially for women [6]. Due to an increased participation of women in the labor market, the number of dualearner families has grown substantially. However, women are frequently regarded as the primary caregivers of the family with the responsibility of housework and caring for children. Therefore, the demands of work and family make it increasingly likely for women to experience work-family conflict compared to men. Moreover, studies have shown that female medical professionals are more vulnerable to experiencing work-family conflict due to struggling with their work and family responsibilities $[1,7,8]$. Work-family conflict does not only affect women by limiting the opportunity for a leadership position in their career and their professional activity [9], but also negatively affects their mental health among female employees $[10,11]$. In addition, one study demonstrated that female medical staff who suffer greater work-family conflict were more likely to develop mental health problems compared to male counterparts [12] .

Burnout is another factor that contributes to mental health issues among medical professionals [2]. Burnout refers to "a psychological syndrome emerging as a prolonged response to chronic interpersonal stressors on the job," and it includes emotional exhaustion, depersonalization, and reduced personal accomplishment [13]. Emotional exhaustion is a feeling of excessive emotional stress and feeling drained from interaction with other people, and is the core element of burnout [14]. Higher workload is the main reason for higher emotional exhaustion [15]. As healthcare providers commonly suffer from their demanding jobs, longer work hours, and regular night shifts, they are likely to experience emotional exhaustion. Additionally, it has been postulated that emotional exhaustion is associated with work-related crisis, such as job withdrawal, dissatisfaction, and intention to leave [16]. People who suffer a high level of work-family conflict are likely to develop emotional exhaustion toward their current career [17], and emotional exhaustion is positively associated with psychological health problems [18]. Furthermore, a study has proposed that work-family conflict is significantly correlated with emotional exhaustion among female medical professionals compared with their male colleagues [19]. These findings have suggested that emotional exhaustion may have a crucial role in helping understand the relationship between work-family conflict and mental health among female medical professionals. However, much uncertainty still exists about the relationship between emotional exhaustion, work-family conflict, and anxiety symptoms among female medical professionals.

When individuals experience distress, social support can be considered to be a coping strategy [20]. Social support refers to the perceived availability of resources, involving support offered by the individual's social networks, such as spouses, friends, co-workers, and families [21]. It has been previously shown that social support can significantly reduce the detrimental effect of stressful conditions to prevent mental problems for individuals [21]. Social support can have positive impacts on health via two effects: a direct effect and a buffering effect [21]. A large and growing body of literature has proposed that social support is negatively associated with psychological distress [22-25]. Evidence suggests that social support has beneficial impacts on anxiety symptoms among medical professionals [26]. Regarding the buffering effect of social support, previous research has established that it can be seen as a moderator between burnout and anxiety symptoms [27]. Furthermore, it has also been proposed that social support can moderate the effect of work-family conflict on burnout [28]. It is observed that the positive impact of social support is more apparent for female medical staff compared to their male counterparts [29]. There is little published data on exploring when social support moderates the relationships between work-family conflict, social support, emotional exhaustion and anxiety symptoms among female medical professionals.

This study seeks to explore the important mechanisms between work-family conflict, social support, emotional exhaustion, and anxiety symptoms among female medical professionals. The natural characteristics of gender and profession are highly correlated with work-family conflict and anxiety symptoms, and little is known about these mechanisms among this population. This study 
focuses on emotional exhaustion as one mechanism that may explain the association between work-family conflict and anxiety symptoms. Moreover, this study explores the moderating effect of social support in such mechanism. By doing so, potential methods to improve mental health among female medical professionals experiencing can be identified.

\section{Theoretical background}

In line with the Job Demand-Resources Model (J-DR model), job characteristics can be classified into two categories: job demands and job resources. Job demands are 'negative aspects', like a heavy workload, work-family conflict, and job uncertainty [30, 31]. In contrast, job resources are defined as 'positive aspects' that refers to social support and room for personal growth and development $[30,31]$. The J-DR model consists of a motivational process and a health impairment process [30,31].

This study focused on the health impairment process, which implies that excessive job demands can increase the risk for burnout and result in negative outcomes, such as health problems (e.g. anxiety) [32]. Work-family conflict can be regarded as one form of job demands [33], and emotional exhaustion is the core of burnout [13]. In the health impairment process, individuals with work-family conflict find that work demands deplete their resources, which makes it difficult for them to meet familial expectations. Furthermore, inadequate recovery causes emotional exhaustion. In the long term, emotional exhaustion can drain employees' mental and physical resources and therefore contribute to mental health problems, such as anxiety and depression [32]. This means that the effect of work-family conflict can predict emotional exhaustion, resulting in anxiety symptoms. The mediating role of emotional exhaustion in the health impairment process can be found in previous studies. For example, research conducted by Santa et al. (2018) has shown that job demands predicted higher levels of anxiety through emotional exhaustion [34]. Thus, the following hypothesize is formed:

Hypothesis 1: The effect of work-family conflict on anxiety symptoms will be mediated by emotional exhaustion.

In the health impairment process, job resources play an important role in buffering the effect of work-family conflict on burnout [35]. Social support can be an important job resource due to its buffering effect. When stressful events have a negative effect on an individual's wellbeing, the presence of social support can serve as a protective factor. Social support can help an individual minimize the stress they perceive or adopt healthy behaviors in response to stressors [21]. Existing research recognizes the critical role played by social support. For example, Huang et al. (2015) in a study among nurses found a moderating effect of social support on the relationship between work-family conflict and burnout [28]. Therefore, in line with the J-DR model, we consider that social support can be seen as a moderator in the health impairment process. Thus, the following hypothesize is formed:

Hypothesis 2: Social support from private life and work life (e.g., co-workers and family) moderates the mediating effect of emotional exhaustion on the relationship between work-family conflict and anxiety symptoms.

Based on above, the conceptual model is presented in Fig. 1.

This research contribution is threefold. First, the issue of work-family conflict has received considerable critical attention, but far less work has been done to explain how work-family conflict is related to anxiety symptoms and the role that emotional exhaustion has plays among this population. Second, although some progress has been made in advancing the understanding of the role of social support, it is important to know if social support moderates the effect of work-family conflict on anxiety symptoms via emotional exhaustion among this population. Third, empirical evidence is provided to identify workplace interventions for policy makers.

\section{Methods}

\section{Study units and participants}

A convenience sample was used in this study. Data were collected by three trained researchers from May 2019 to August 2019. Female nurses and physicians were recruited from the Guizhou Provincial People's Hospital, the affiliated hospital of Guizhou Medical University, Puan People's Hospital, and Sir Run Run Shaw Hospital.

The researchers contacted nurse managers from the hospitals to acquire consent to participate in this study. If nurse managers agreed, they were asked to provide the number of female physicians and nurses working in their wards. A total of 861 female nurses and physicians

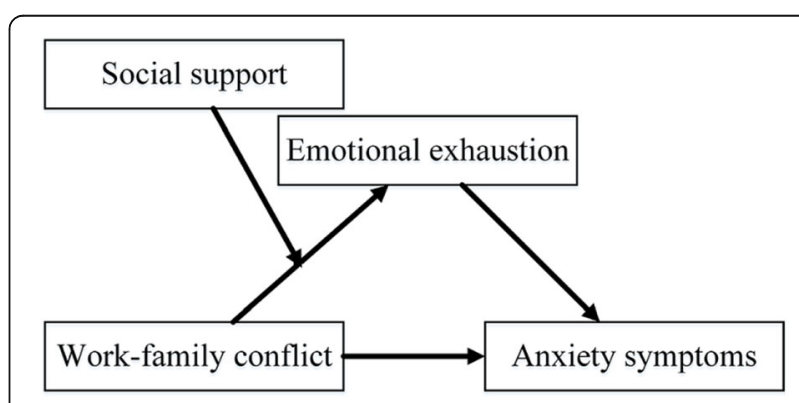

Fig. 1 Conceptual model 
from the hospitals were invited to participate. The researchers explained the aims of the study to each female physician or nurse, and these medical staff made an informed decision about participation in the study. Twenty participants refused participation in the study. Selfadministered paper-pencil questionnaires were distributed to the remaining 841 participants. All participants were informed that questionnaires were anonymous, and the collected data were kept confidential. The survey was completed by 769 participants resulting in a response rate of $91.4 \%$. Participants were excluded from the final sample if they failed to provide any responses to the key variables examined. The final study sample included 764 participants.

\section{Measures}

\section{Anxiety symptoms}

Anxiety symptoms were measured using the Zung SelfRating Anxiety Scale (SAS) [36]. The Chinese version of the SAS was chosen for this study [37]. The SAS has 20 items and each item is scored on a 4-point Likert scale (e.g., "I feel like I'm falling apart and going to pieces"). Higher index scores reflect higher levels of anxiety [38]. The Cronbach's alpha was 0.71 .

\section{Social support}

The Social Support Rating Scale (SSRS), developed by a Chinese researcher, was used to evaluate social support in this study [39]. SSRS assesses received support and perceived support from private life and work life (e.g., supervisors, co-workers, and family). There are three dimensions (objective support, subjective support, and the usage of support) in this Chinese questionnaire. Fourteen items were scored on four-point Likert scales, and these items ranged from one to four (e.g., "How many intimate friends do you have, from whom you can receive support and help?"). Higher scores reflect more social support given. The Cronbach's alpha coefficient for SSRS was 0.70 .

\section{Work-family conflict}

Work-family conflict was measured using the workfamily conflict questionnaire [40]. The Chinese version of the work-family conflict questionnaire contains five items with a seven point Likert scale (e.g., "your job reduces the amount of time you can spend with the family") [41]. Higher scores indicate higher levels of work-family conflict. The Cronbach's alpha coefficient was 0.94 .

\section{Emotional exhaustion}

The Chinese Burnout Inventory [42] was used to measure burnout. This questionnaire includes 15 items and three dimensions (emotional exhaustion, depersonalization, and reduced personal accomplishment). One of the major dimensions is emotional exhaustion. This dimension consists of five items (e.g., "I feel emotionally drained from my work"), and the subscale was adopted for this study. Higher scores indicate higher levels of emotional exhaustion. The Cronbach's alpha coefficient was 0.94 .

\section{Statistical analysis}

Descriptive analysis, factor analysis, and pearson correlational analyses of the four variables (anxiety symptoms, social support, work-family conflict, and emotional exhaustion) were performed using IBM $^{\circ}$ SPSS $^{\bullet}$ Statistics, (Version 24, IBM Corporation, New York, NY). Model 4 and model 7 of PROCESS macro were adapted to test the significance of the mediation model (H1) and moderated mediation model (H2), respectively. The approach of PROCESS macro is based on ordinary least-squares regression [43]. The biascorrected bootstrap procedure was applied, as this technique does not assume a normal distribution of effects, and it typically has higher power than the percentile bootstrap procedure [44]. Moreover, the biascorrected bootstrap has a low risk of elevated Type I error rate in large sample sizes (i.e. > 500) [44]. The number of bootstrap samples was 5000 in this study. Point estimates were considered significant if the bias-corrected bootstrap 95\% confidence interval did not contain zero. An "index of moderated mediation" was generated by using a bootstrap confidence interval, which was recommended by Hayes (2015) [45]. A significant moderated mediation effect means that the bias-corrected bootstrap 95\% confidence interval of this index is different from zero. As the PROCESS macro also can visualize interactions, the pick-a-point approach was applied for probing interactions [46].

\section{Results}

Preliminary analyses

Table 1 presents the descriptive statistics, correlation matrix, and average variance extracted (AVE). Each AVE exceeded 0.50 . This indicates adequate convergent validity. The square of root of AVE values (0.70-0.87)

Table 1 Correlation coefficient, mean, standard deviation, and AVE

\begin{tabular}{llllllll}
\hline Variables & M & SD & AVE & 1 & 2 & 3 & 4 \\
\hline 1 SS & 2.68 & 0.78 & 0.50 & $\mathbf{0 . 7 0}$ & & & \\
2 EE & 2.75 & 1.51 & 0.75 & $-0.27^{\mathrm{a}}$ & $\mathbf{0 . 8 7}$ & & \\
3 WFC & 3.10 & 0.95 & 0.74 & $-0.29^{\mathrm{a}}$ & $0.54^{\mathrm{a}}$ & $\mathbf{0 . 8 6}$ & \\
4 AS & 1.68 & 0.53 & 0.62 & $-0.21^{\mathrm{a}}$ & $0.34^{\mathrm{a}}$ & $0.36^{\mathrm{a}}$ & $\mathbf{0 . 7 9}$ \\
\hline
\end{tabular}

SS Social support, EE Emotional exhaustion, WFC Work-family conflict, AS Anxiety symptoms, AVE average variance extracted

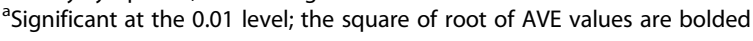


exceeded the construct correlation values $(-0.29-0.54)$, which suggests that discriminant validity is satisfactory.

\section{Mediation analyses}

Model 4 of PROCESS macro was adapted to test if emotional exhaustion mediated the association between work-family conflict and anxiety symptoms. Results showed that work-family conflict was related to anxiety symptoms directly $(b=0.14,95 \% \mathrm{CI}[0.09$, $0.18]$ ), and work-family conflict was associated with anxiety symptoms indirectly through emotional exhaustion $(b=0.06,95 \% \mathrm{CI}[0.04,0.09])$ (Table 2). This supports hypothesis 1 .

\section{Moderated mediation analyses}

The results of model 7 of PROCESS indicated that social support moderated the relationship between work-family conflict and emotional exhaustion $(b=-0.12, p=0.03)$. The pick-a-point measure was adopted to probe the interaction. Figure 2 further revealed that work-family conflict was more strongly related to emotional exhaustion at a low level of social support $(b=0.90, p<0.001)$ compared to a high level of social support ( $\mathrm{b}=0.71, p<$ 0.001 ). As shown in Table 3, the indirect effect of workfamily conflict on anxiety symptoms was strongest at the lowest $(-1 \mathrm{SD})$ level of social support and weakest for those who were at higher levels $(+1 \mathrm{SD})$ of social support. The confidence intervals of moderated mediation index did not contain zero $(b=-0.01,95 \%$ CI $[-0.02$, $0.01]$ ), so this index was found to be significant. This supported hypothesis 2 .

\section{Discussion}

Work-family conflict can be an important issue for women as females are traditionally tasked with managing familial responsibilities (e.g. child rearing, household chores), which can have a detrimental impact on their wellbeing [11]. Female medical professionals are more likely to suffer work-family conflict leading to mental problems due to an overly demanding work environment. The potential influence of work-family conflict on female medical staff has drawn increased attention from psychologists and policy makers. This study investigated how and when work-family conflict affected anxiety symptoms, and the results contribute to highlighting the need to develop programs to help female physicians and nurses. The effect of work-family conflict on anxiety symptoms through emotional exhaustion was found to be conditional on social support of this female population.

The results indicate that work-family conflict has a direct effect on anxiety symptoms. This suggests that if the stressors of work-family conflict are chronic, mental health problems may arise [47]. This is because chronic demands in one domain require sustained physical and/or mental effort. The continual depletion of energy eventually results in physiological and psychological costs, leading to negative long-term outcomes (e.g., mental health problems). These results are consistent with previous work that has observed that female nurses experiencing work-family conflict disproportionately suffer from psychophysical health conditions [48]. Therefore, considering the role of women, flexible work arrangements and part-time jobs may play a vital role in reduction of the effect of work-family conflict on anxiety symptoms among female medical staff [49].

Our results indicate that high levels of work-family conflict are indirectly associated with higher anxiety symptoms, with an increase in emotional exhaustion operating as the mediator. These findings enrich the knowledge on mediating mechanisms, explaining associations between work-family conflict and anxiety symptoms among female medical staff. A previous study also found that emotional exhaustion has significant mediating effects in the link between job stress and anxiety [50]. In line with the J-DR model, emotional exhaustion mediated the relationship between work-family conflict and anxiety symptoms. When an individual experiences work overload for long periods of time, they find they cannot fulfill their

Table 2 Mediation analyses

\begin{tabular}{|c|c|c|c|c|c|c|c|c|c|}
\hline DV & IV & coeff & se & $\mathrm{t}$ & $p$ & $\mathrm{LLCl}$ & ULCI & $F$ & $R^{2}$ \\
\hline \multirow[t]{3}{*}{ AS } & constant & 1.06 & 0.05 & 19.43 & $<.001$ & 0.95 & 1.16 & $78.17^{* * *}$ & 0.16 \\
\hline & $\mathrm{EE}$ & 0.08 & 0.01 & 5.27 & $<.001$ & 0.05 & 0.10 & & \\
\hline & WFC & 0.14 & 0.02 & 6.09 & $<.001$ & 0.09 & 0.18 & & \\
\hline \multirow[t]{3}{*}{$\mathrm{EE}$} & constant & 0.11 & 0.15 & 0.77 & 0.44 & -0.18 & 0.40 & $307.63^{* * *}$ & 0.29 \\
\hline & WFC & 0.85 & 0.05 & 17.54 & $<.001$ & 0.76 & 0.95 & & \\
\hline & Indirect effect & 0.06 & 0.01 & - & - & 0.04 & 0.09 & & \\
\hline
\end{tabular}

Bootstrap sample size $=5000$

DV Dependent variable, IV ndependent variable, ULCI Upper Limit of Confidence Interval, LLCI Lower Limit of Confidence Interval, SS Social support, EE Emotional exhaustion, WFC Work-family conflict, AS Anxiety symptoms, Indirect effect Work-family conflict $\rightarrow$ Emotional exhaustion $\rightarrow$ Anxiety symptoms

*** $p<0.001$ 


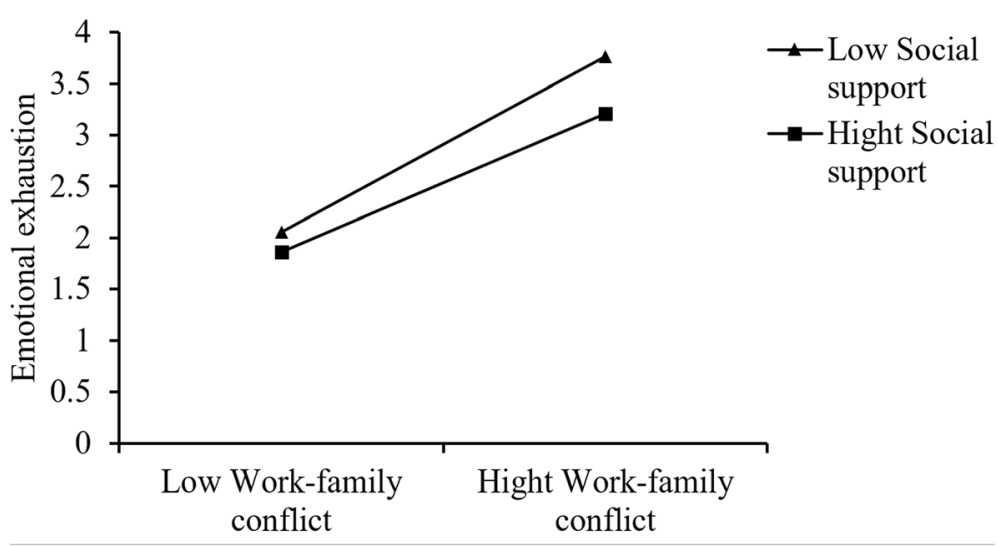

Fig. 2 The interaction between work-family conflict and social support on emotional exhaustion

familial responsibilities. In the long term, this may drain their personal resources, including emotional and mental energy, resulting in mental health problems (e.g., anxiety) during the depletion process.

Drawing on the J-DR model, a model in which the indirect effect of work-family conflict on anxiety symptoms via emotional exhaustion is moderated by social support is proposed. The results of this study support this model and highlight the buffering role of social support in influencing anxiety symptoms through emotional exhaustion among female medical staff. Previous research also supports the moderating effects of social support on work-family conflict and burnout [28]. Moreover, Santa et al. (2018) reported that the indirect effect of job demand on anxiety can be moderated by social support [34]. Based on the JDR model, job resources (e.g., social support) can buffer the effect of job demands (e.g., work-family conflict) on anxiety symptoms via emotional exhaustion. This is because the buffering effect of social support can change individuals' perceptions and cognitions evoked by stressors, and moderate people' appraisal process to stressful events and/or reduce the impact of stressors on health outcomes.

Table 3 Moderated mediation analyses

\begin{tabular}{lllll}
\hline Values of moderators & Indirect effect & SE & LLCl & ULCl \\
\hline Social support & & & & \\
-1 SD & 0.07 & 0.01 & 0.04 & 0.10 \\
M & 0.06 & 0.01 & 0.04 & 0.09 \\
$\quad$ 1 SD & 0.05 & 0.01 & 0.03 & 0.08 \\
Index of moderated mediation & -0.01 & 0.01 & -0.02 & -0.01
\end{tabular}

Outcome variable: Anxiety symptoms. Bootstrap sample size $=5000$ ULCI Upper Limit of Confidence Interval, LLCI Lower Limit of Confidence Interval; Moderated mediation effect: social support moderates the indirect effect of work-family conflict on anxiety symptoms

\section{Practical implications}

Since emotional exhaustion can mediate the effect of work-family conflict on anxiety symptoms, a wide range of action for decreasing emotional exhaustion should be adopted by organizations and individuals.

From an organizational perspective, reducing job demands can be regarded as a vital step to reducing emotional exhaustion and fostering a more positive work-place environment based on J-DR theory [18]. As job demands is associated with burnout (emotional exhaustion), the creation of optimal job demands can be the key to mitigating emotional exhaustion. Hospitals should recruit sufficient human resources to enable each employee to avoid suffering an overly demanding workload and exceedingly high levels of work pressure. Therefore, a supportive organizational climate could help promote well-being while simultaneously reducing emotional exhaustion. From an individual's perspective, certain personality traits can be beneficial, such as emotional stability, conscientiousness, and agreeableness, which can help employees perceive their work environments favorable despite of the challenging nature of their jobs [18]. Related training modules can be designed to teach employees how to improve individuals' personality. Additionally, other individual-level interventions are effective, such as job crafting training, strengths use training, and recovery training [18]. Individuals can adopt these measures to learn how to proactively change their work environment to avoid experiencing emotional exhaustion by setting personal goals, using their strengths for their career, and using relaxation or mindfulness techniques [2].

This study indicates that social support can be a useful resource for female healthcare providers to improve mental health. Individuals can obtain support from their social network, such as coworkers, supervisors, and family. Based on the traditional Chinese culture, it is widely believed in Chinese society that 
women should mainly contribute their time and efforts to the familial domain, regardless of their career development. However, female medical professionals could achieve positive work-life balance if other family members provided a larger proportion of contributions [51]. In particular, grandparent-provided childcare can also be an option, as well as highquality formal childcare services in Chinese dualcareer couples, and women's partners can also take more responsibilities for housework in their spare time [52].

Furthermore, supervisors and colleagues from a supporting network are crucial to female medical staff. Supportive supervisors can help female nurses and physicians handle critical patients properly and effectively by providing personal coaching. These supervisors can also provide them with the confidence to achieve high-quality standards in their work across many different tasks [53, 54]. Meanwhile, supportive colleagues can offer help to cover additional work when female nurses and physicians suffer from irregular and long working hours. The understanding and support from colleagues can enable female nurses and physicians to relax and feel less anxious, so they are less likely to develop emotional exhaustion and anxiety.

\section{Study limitations}

It is important to consider some limitations to this study. First, this was a cross-sectional study, so causal relationships between these variables cannot be established and the reciprocal direction of the relationships cannot be determined based on the results. For example, anxiety symptoms could also influence burnout. Longitudinal and experimental research in the future are required to draw reliable and firm conclusions. Second, self-reported measures were adopted in this study, which may raise concerns about common method variance causing an overestimation. Future studies are encouraged to adopt objective rather than subjective measures. For example, criteria of Diagnostic and Statistical Manual of Mental Disorders (DSM) can be used by mental health professionals to diagnose anxiety. Third, the direction of family-to-work conflict was not considered, which may also play a vital role in the process of the effect of work-family conflict on anxiety symptoms. However, this study focused on the direction of work-to-family conflict, because this direction is more likely to relate to job demand [55], which is one of the core factors of emotional exhaustion. Additionally, the moderating effect of social support in this study was tested, but other personal resources (e.g., self-efficacy and optimism) that may be effective should also be considered in the future based the proposed model. Fourth, future studies should examine whether work-family conflict could predict anxiety symptoms via other dimensions of burnout (e.g., depersonalization and reduced personal accomplishment). Fifth, control variables were not included in this study. However, a critical review suggested that researchers should include control variables based on theoretical justifications, rather than early empirical associations or defaulting to "they might associate" with the investigated variables [56]. Finally, the results are only based on females, which means that the findings cannot be generalized to both genders in hospitals. Future studies could incorporate females and males into this proposed model to explore the relationships between these key factors.

\section{Conclusion}

These findings suggest a role for emotional exhaustion and social support in promoting mental health among female medical staff. Policymakers should realize that healthy female employees can perform better at hospitals, and thus consistently contribute towards accomplishing organizational goals. Necessary measures should be adopted to effectively support them. Female medical staff need to raise awareness of the role of social support and emotional exhaustion, which can affect their mental health.

\section{Abbreviations \\ Cl: Confidence Interval; OR: Odds Ratio; DV: Dependent variable; IV: Independent variable; ULCI: Upper Limit of Confidence Interval; LLCI: Lower Limit of Confidence Interval; SPSS: Statistical Package for Social Sciences; SSRS: Social Support Rating Scale; SAS: Zung Self-Rating Anxiety \\ Scale; SS: Social support; EE: Emotional exhaustion; WFC: Work-family conflict; AS: Anxiety symptoms}

\section{Acknowledgements}

The first author wants to thank Mr. Liangyuan Li, who provided her with tremendous assistance.

\section{Authors' contributions}

$\mathrm{HZ}$ and $\mathrm{ZHY}$ designed the study, $\mathrm{HZ}, \mathrm{ZHY}$ and LWT analyzed the data, and drafted the manuscript and interpreted the data. HZ, ZHY, SYM and PZ revised the manuscript. GJQ, JS, MW, and QZ participated in the data collection. All authors read and approved the final manuscript.

Funding

None.

\section{Availability of data and materials}

The datasets used and analyzed during the current study are available from the corresponding author on reasonable request.

\section{Ethics approval and consent to participate}

Ethical approval was obtained from ethics committee of Guizhou Provincial People's Hospital, the affiliated hospital of Guizhou Medical University, and Sir Run Run Shaw Hospital. The study was performed in accordance with the ethical principles set forth in Helsinki declaration. Written informed consent was obtained from all participants.

Consent for publication

Not applicable. 


\section{Competing interests}

The authors declare that they have no competing interests.

\section{Author details}

'Zhejiang University School of Medicine Sir Run Run Shaw Hospital, Hangzhou 310016, Zhejiang, China. ${ }^{2}$ School of Nursing, Nipissing University, Toronto, Ontario, Canada. ${ }^{3}$ Department of cardiology, Guizhou Provincial People's Hospital, Guiyang, Guizhou, China. ${ }^{4}$ The affiliated hospital of Guizhou Medical University, Guiyang, Guizhou, China. ${ }^{5}$ Nursing College of Chongqing Medical University, Chongqing, China.

\section{Received: 16 December 2019 Accepted: 18 May 2020} Published online: 29 May 2020

\section{References}

1. Nomura K, Yamazaki Y, Gruppen LD, Horie S. The difficulty of professional continuation among female doctors in Japan: a qualitative study of alumnae of 13 medical schools in Japan. BMJ Open. 2015;5(3):e005845.

2. Petrie K, Crawford J, Baker STE, Dean K. Interventions to reduce symptoms of common mental disorders and suicidal ideation in physicians: a systematic review and meta-analysis. Lancet Psychiatry. 2019;6(3):225-34.

3. Győrffy Z, Dweik D, Girasek E. Workload, mental health and burnout indicators among female physicians. Hum Resour Health. 2016;14(1):12.

4. Harvey SB, Modini M, Joyce S, Milligan-Saville JS, Tan L, Mykletun A, Bryant RA, Christensen H, Mitchell PB. Can work make you mentally ill? A systematic meta-review of work-related risk factors for common mental health problems. Occup Environ Med. 2017;74(4):301-10.

5. Greenhaus JH, Parasuraman S. Vocational and organizational behavior, 1985: a review 추. J Vocat Behav. 1986;29(2):115-76.

6. Allen TD, Martin A. The work-family interface: a retrospective look at 20 years of research in JOHP. J Occup Health Psychol. 2017;22(3):259-72.

7. Mikol F, Franc C. Gender differences in the incomes of self-employed French physicians: the role of family structure. Health Policy. 2019;123(7) 666-74.

8. Sugawara N, Danjo K, Furukori H, Sato Y, Tomita T, Fujii A, Nakagami T, Kitaoka K, Yasuifurukori N. Work-family conflict as a mediator between occupational stress and psychological health among mental health nurses in Japan. Neuropsychiatric Dis Treat. 2017;13:779-84.

9. Cigarán-Méndez M, Jiménez-Antona C, Parás-Bravo P, Fuensalida-Novo S, Rodríguez-Jiménez J, Fernández-de-las-Peñas C. Active trigger points are associated with anxiety and widespread pressure pain sensitivity in women, but not men, With Tension Type Headache. Pain Pract. 2019;19(5):522-9.

10. Carvalho VS, Chambel MJ. Perceived high-performance work systems and subjective well-being: work-to-family balance and well-being at work as mediators. J Career Dev. 2016;43(2):0894845315583113.

11. Zhou S, Da S, Guo H, Zhang X. Work-family conflict and mental health among female employees: a sequential mediation model via negative affect and perceived stress. J Front Psychol. 2018;9:544

12. Guille C, Frank E, Zhao Z, Kalmbach DA, Nietert PJ, Mata DA, Sen S. Workfamily conflict and the sex difference in depression among training physicians. JAMA Intern Med. 2017;177(12):1766-72.

13. Maslach C, Leiter MP. Understanding the burnout experience: recent research and its implications for psychiatry. World Psychiatry. 2016;15(2): 103-11

14. Maslach C, Schaufeli WB, Leiter MP. Job burnout. Annu Rev Psychol. 2001; 52(1):397-422

15. Bogaert PV, Peremans L, Heusden DV, Verspuy M, Kureckova V, Cruys ZVD, Franck E. Predictors of burnout, work engagement and nurse reported job outcomes and quality of care: a mixed method study. BMC Nurs. 2017;16(1):5.

16. Aiken LH, Sermeus W, Van den Heede K, Sloane DM, Busse R, McKee M, Bruyneel L, Rafferty AM, Griffiths P, Moreno-Casbas MT. Patient safety, satisfaction, and quality of hospital care: cross sectional surveys of nurses and patients in 12 countries in Europe and the United States. BMJ Open. 2012;344:e1717.

17. Yustina Al, Valerina T. Does work-family conflict affect the auditor's performance?: examining the mediating roles of emotional exhaustion and job satisfaction. Gadjah Mada Int J Bus. 2018;20(1):89.

18. Bakker AB, Demerouti E, Sanzvergel Al. Burnout and work engagement: the JD-R approach. Ann Review Organizational Psychol Organizational Behavior. 2014;1(1):389-411.
19. Dreher A, Theune M, Kersting C, Geiser F. Prevalence of burnout among German general practitioners: comparison of physicians working in solo and group practices. PLoS One. 2019;14(2):e0211223.

20. Latkin CA, Knowlton AR. Social network assessments and interventions for health behavior change: a critical review. J Behavioral Med. 2015;41(3):90-7.

21. Cohen S, Wills T. Stress, social support, and the buffering hypothesis. Psychol Bull. 1985;98(2):310.

22. Kornblith AB, Herndon JE 2nd, Zuckerman E, Viscoli CM, Horwitz RI, Cooper MR, Harris L, Tkaczuk KH, Perry MC, Budman D, et al. Social support as a buffer to the psychological impact of stressful life events in women with breast cancer. Cancer. 2001;91(2):443-54.

23. Lau Y, Wong DFK, Wang Y, Kwong DHK, Wang Y. The roles of social support in helping Chinese women with antenatal depressive and anxiety symptoms cope with perceived stress. Arch Psychiatr Nurs. 2014;28(5):30513.

24. Lin HS, Probst JC, Hsu YC. Depression among female psychiatric nurses in southern Taiwan: main and moderating effects of job stress, coping behaviour and social support. J Clin Nurs. 2010;19(15-16):2342-54.

25. Maheri A, Sadeghi R, Shojaeizadeh D, Tol A, Yaseri M, Rohban A. Depression, anxiety, and perceived social support among adults with Beta-thalassemia major: cross-sectional study. Korean J Fam Med. 2018;39(2):101-7.

26. Yu-Qin G, Bo-Chen P, Wei S, Hui W, Jia-Na W, Lie W. Anxiety symptoms among Chinese nurses and the associated factors: a cross sectional study. BMC Psychiatry. 2012;12(1):141.

27. Zhang H, Ye ZH, Tang $L$, et al. Anxiety symptoms and burnout among Chinese medical staff of intensive care unit: the moderating effect of social support[J]. BMC psychiatry, 2020;20:1-7.

28. Huang HY, Wu KS, Wang ML, Tang PS. Moderating the effect of supervisor support on work-to-family conflict and burnout relationship. Stud EthnoMed. 2015;9(2):263-78.

29. Gattino S, De Piccoli N, Grosso MS, Miozzo S: Awareness of gender medicine among family doctors. A field investigation. J Prevention Intervention Community 2019:1-14.

30. Bakker AB, Demerouti $E$. The job demands-resources model: state of the art. J Manag Psychol. 2007;22:309-28.

31. Demerouti $E$, Bakker AB, Nachreiner F, Schaufeli WB. The job demandsresources model of burnout. J Appl Psychol. 2001;86(3):499.

32. Schaufeli $W$. The job demands-resources model: a 'how to'guide to increase work engagement and prevent burnout. Organ Dyn. 2017;46:120-32.

33. Bakker AB, Van Emmerik H. P. VR: how job demands, resources, and burnout predict objective performance: a constructive replication. Anxiety Stress Coping. 2008;21(3):309-24.

34. Santa Maria A, Wörfel F, Wolter C, Gusy B, Rotter M, Stark S, Kleiber D, Renneberg B. The role of job demands and job resources in the development of emotional exhaustion, depression, and anxiety among police officers. Police Q. 2018;21(1):109-34.

35. Bakker $A B$, Demerouti $E$. Job demands-resources theory: taking stock and looking forward. J Occup Health Psychol. 2017;22(3):273.

36. Zung WW. A rating instrument for anxiety disorders. Psychosomatics. 1971; 12(6):371-9.

37. Wang Z, Chi Y. Chinese version of Zung's self-rating anxiety scale. Shanghai Psychiatry. 1984;2:73-4.

38. Gong Y, Han T, Chen W, Dib HH, Yang G, Zhuang R, Chen Y, Tong X, Yin X, Lu Z. Prevalence of anxiety and depressive symptoms and related risk factors among physicians in China: a cross-sectional study. PLoS One. 2014; 9(7):e103242.

39. Xiao S. The theoretical basis and application of social support questionnaire. J Clin Psychol Med. 1994;4:98-100.

40. Netemeyer RG, Boles JS, Mcmurrian R. Development and validation of workfamily conflict and family-work conflict scales. J Appl Psychol. 1996;81(4): 400-10.

41. Li Y, Zhao N. Structure and measurement of work-family support and its moderation effect. Acta Psychol Sin. 2009;41:863-74.

42. Li Y, Li Y. Developing the diagnostic ctiterion of job burnout. Psychol SciShanghai. 2006;29(1):148

43. Hayes AF. Introduction to mediation, moderation, and conditional process analysis. J Educ Meas. 2013;51(3):335-7.

44. Fritz MS, Taylor AB, Mackinnon DP. Explanation of two anomalous results in statistical mediation analysis. Multivar Behav Res. 2012;47(1):61-87.

45. Hayes AF. An index and test of linear moderated mediation. Multivar Behav Res. 2015;50(1):1-22. 
46. Hayes AF, Rockwood NJ. Regression-based statistical mediation and moderation analysis in clinical research: observations, recommendations, and implementation. Behav Res Ther. 2017;98:39-57.

47. Ten Brummelhuis $L L$, Bakker $A B$. A resource perspective on the work-home interface: the work-home resources model. Am Psychol. 2012;67(7):545.

48. Zurlo MC, Vallone F, Smith AP: Work-family conflict and psychophysical health conditions of nurses: Gender differences and moderating variables. Jpn J Nurs Sci 2020:e12324.

49. Pas B, Peters P, Doorewaard H, Eisinga R, Lagro-Janssen T. Feminisation of the medical profession: a strategic HRM dilemma? The effects of familyfriendly HR practices on female doctors' contracted working hours. Hum Resour Manag J. 2011;21(3):285-302.

50. Chen J, Li J, Cao B, Wang F, Luo L, Xu J. Mediating effects of self-efficacy, coping, burnout, and social support between job stress and mental health among young Chinese nurses. J Adv Nurs. 2020;76(1):163-73.

51. Shu Y, Huang L. The study of the gender discrimination from the perspective of multimodal critical discourse analysis a case study of the image construction of a TV commercial Advertisemen. Int I Soc Sci Universities. 2019;2(2):126-34.

52. Du F. Dong X-y, Zhang Y: grandparent-provided childcare and labor force participation of mothers with preschool children in urban China. China Population Development Stud. 2019:2(4):347-68.

53. Kaderli R, Muff B, Stefenelli U, Businger A. Female surgeons' mentoring experiences and success in an academic career in Switzerland. Swiss Med Wkly. 2011;141:w13233.

54. Minamizono S, Nomura K, Inoue Y, Hiraike H. Gender division of labor, burnout, and intention to leave work among young female nurses in Japan: a cross-sectional study. Int J Environ Res Public Health. 2019;16(22):2201.

55. Li A, Mccauley KD, Shaffer JA. The influence of leadership behavior on employee work-family outcomes: a review and research agenda. Hum Resour Manag Rev. 2017;27(3):S1053482217300190.

56. Bernerth $\mathrm{JB}$, Aguinis H. A critical review and best-practice recommendations for control variable usage. Pers Psychol. 2016;69(1):229-83.

\section{Publisher's Note}

Springer Nature remains neutral with regard to jurisdictional claims in published maps and institutional affiliations.

Ready to submit your research? Choose BMC and benefit from:

- fast, convenient online submission

- thorough peer review by experienced researchers in your field

- rapid publication on acceptance

- support for research data, including large and complex data types

- gold Open Access which fosters wider collaboration and increased citations

- maximum visibility for your research: over $100 \mathrm{M}$ website views per year

At $\mathrm{BMC}$, research is always in progress.

Learn more biomedcentral.com/submissions 